\title{
Freqüência das infecções pelo HIV-1, rubéola, sífilis, toxoplasmose, citomegalovírus, herpes simples, hepatite $B$, hepatite C, doença de Chagas e HTLV I/II em gestantes, do Estado de Mato Grosso do Sul
}

\author{
Frequency of HIV-1, rubella, syphilis, toxoplasmosis, cytomegalovirus, simple \\ herpes virus, hepatitis B, hepatitis C, Chagas' disease and HTLV I/II infection \\ in pregnant women of State of Mato Grosso do Sul
}

\section{Ernesto Antonio Figueiró-Filho ${ }^{1}$, Flávio Renato de Almeida Senefonte ${ }^{1}$, Alessandro Henrique Antunes Lopes ${ }^{1}$, Orlando Oliveira de Morais', Virgílio Gonçalves Souza Júnior ${ }^{1}$, Tamara Lemos Maia ${ }^{1}$ e Geraldo Duarte ${ }^{1}$}

\section{RESUMO}

Objetivou-se avaliar a freqüência das infecções por sífilis, rubéola, hepatite B, hepatite C, toxoplasmose, doença de Chagas, HTLV I/II, herpes simples, HIV-1 e citomegalovírus em gestantes e relacionar a faixa etária das pacientes com a freqüência das infecções. Estudo transversal de 32.512 gestantes submetidas à triagem pré-natal no período de novembro de 2002 a outubro de 2003. As freqüências encontradas foram de 0,2\% para infecção pelo vírus HIV-1, 0,03\% para rubéola, 0,8\% para sífilis, 0,4\% para toxoplasmose, 0,05\% para infecção aguda pelo citomegalovírus, 0,02\% pelo vírus herpes simples, 0,3\% para hepatite B (HBsAg), 0,1\% para hepatite C, 0,1\% para HTLV I/II e 0,1\% para doença de Chagas. Houve associação significativa entre faixa etária e infecções por rubéola, citomegalovírus, doença de Chagas e herpes vírus. As freqüências de rubéola, sifilis, toxoplasmose, doença de Chagas e citomegalovírus nas gestantes encontram-se abaixo dos valores descritos na literatura.

Palavras-chaves: Soroprevalência. Pré-natal. Transmissão vertical. Transmissão perinatal.

\section{ABSTRACT}

It was aimed to estimate the frequency of syphilis, rubella, hepatitis B, hepatitis C, toxoplasmosis, Chagas' disease, HTLV I/II, simple herpes virus, HIV-1 and cytomegalovirus in pregnant women and to evaluate the relationship between age and the frequency of the infections studied. A transversal study of 32,512 pregnant women submitted to pre-natal sreening in the period of November 2002 to October 2003. The frequency of the tried infections among the pregnant women were $0.2 \%$ of HIV-1, $0.03 \%$ of rubella, $0.8 \%$ of syphilis, $0.4 \%$ of toxoplasmosis, $0.05 \%$ of cytomegalovirus, $0.02 \%$ of simple herpes virus, $0.3 \%$ of HBsAg, $0.1 \%$ of hepatitis C, $0.1 \%$ of HTLV and $0.1 \%$ of Chagas' disease. There was significative statistical association between age and prenatal infection of rubella, cytomegalovirus, Chagas' disease and herpes virus. The rates of frequency of rubella, syphilis, toxoplasmosis, Chagas' disease and cytomegalovirus in pregnant women studied were lower than the compared rates.

Key-words: Seroprevalence. Pre-natal. Vertical transmission. Perinatal transmission.

0 período gestacional não é isento de infecções que comprometam a saúde materno-fetal, de forma especial aquelas que se apresentam assintomáticas ou subclínicas. Nessas situações, o tratamento, em geral, não seria necessário. Entretanto, os riscos da transmissão materno-fetal (vertical) são fatores limitantes para o desenvolvimento e vitalidade do futuro concepto ${ }^{919}$.

No Brasil, doenças infecciosas durante a gravidez são relativamente freqüentes, afetando especialmente populações menos favorecidas. Tal situação cria desafios à saúde pública, para planejar estratégias de triagem dessas doenças de modo prático e abrangente, facilitando o manejo clínico das gestantes com o diagnóstico desses casos. Tal alcance contribui na redução da morbi-mortalidade materno-fetal e conseqüente melhora dos indicadores de saúde de uma determinada região ${ }^{919}$.

Mulheres grávidas quando acometidas por infecções causadas pelos agentes etiológicos, a exemplo do vírus da

1. Departamento de Gineco-Obstetrícia, Faculdade de Medicina, Universidade Federal de Mato Grosso do Sul, Campo Grande, MS.

Endereço para correspondência: Dr. Ernesto Antonio Figueiró-Filho. Rua Nagib Ourives 175, Carandá Bosque I, $79032-424$ Campo Grande, MS

Tel: 5567 3042-5005; 3327-2243; 8406-9261

e-mail: eafigueiro@uol.com.br

Recebido para publicação em 7/2/2006

Aceito em 20/3/2007 
imunodeficiência humana, Trypanossoma cruzi, hepatites virais B e C, vírus da rubéola, Treponema pallidum, vírus herpes simples, citomegalovírus (CMV), HTLV I e II e Toxoplasma gondii, podem transmití-los verticalmente. Tal transmissão pode ocorrer durante a gestação, no momento do parto ou durante 0 aleitamento materno.

Diante do exposto, uma ampla triagem diagnóstica destas infecções durante o período pré-natal possibilita condutas precoces para que a transmissão vertical seja evitada minimizando os malefícios à saúde fetal ${ }^{9}$.

Sendo assim, em função da elevada incidência de doenças sexualmente transmissíveis no Brasil e no Estado de Mato Grosso do Sul e sendo escassas as informações sobre prevalência das infecções de transmissibilidade vertical, objetivou-se no presente estudo a obtenção da frequiência destas infecções em nosso meio. Foi ainda objetivo do trabalho relacionar a distribuição por faixa etária das gestantes com a frequiência dos casos das infecções estudadas.

\section{MATERIAL E MÉTODOS}

Estudo predominantemente descritivo, observacional, transversal, de 32.512 gestantes submetidas à triagem pré-natal no período de novembro de 2002 a outubro de 2003. 0 total de 32.512 gestantes corresponde a $100 \%$ da amostra estudada no período. A triagem incluiu uma investigação sorológica de 10 infecções (HIV 1 e 2, HBSAg e anti-HBC, hepatite C, HTLV I e II, toxoplasmose IgM e IgG, doença de Chagas, herpes simples 1 e 2 IgM e IgG, sífilis ELISA, citomegalovírus IgM e IgG e rubéola $\operatorname{IgM}$ e $\operatorname{IgG})$ e fenilcetonúria materna (PKU), através da técnica de papel filtro.

A gestante ao iniciar o acompanhamento médico pré-natal recebe solicitação da coleta de gota de sangue digital para 0 papel filtro, que é enviado do posto de coleta até o laboratório do Instituto de Pesquisa, Ensino e Diagnóstico (IPED) da APAE de Campo Grande-MS, conveniado à Secretaria Estadual de Saúde, com apoio das Secretarias Municipais de Saúde do Estado de Mato Grosso do Sul. Deste laboratório partem os resultados para os respectivos centros de triagem, solicitando nova coleta se os testes forem positivos ou indeterminados. Neste caso, a nova coleta, com amostra de soro, destina-se ao Laboratório Central (LACEN) da Fundação Serviços Estaduais de Saúde para contraprova e confirmação diagnóstica. Os casos confirmados são encaminhados aos serviços de referência municipais, estaduais e federais, devendo iniciar protocolos específicos de tratamento estabelecidos pelo Ministério da Saúde.

Este programa de triagem é conhecido como programa de proteção a gestante do Estado de Mato Grosso do Sul (PPG-MS), com cobertura de $100 \%$ dos municípios do estado, atingindo cerca de $98 \%$ das gestantes atendidas pelo Sistema Único de Saúde (SUS).

A técnica do papel filtro consiste na coleta de sangue das pacientes, proveniente da polpa digital ou de punção venosa, com deposição no papel filtro em área previamente demarcada.
Após secagem da amostra (até quatro horas), o papel filtro é enviado ao laboratório IPED-APAE em Campo Grande, não ultrapassando período superior a 24 horas após a coleta. Após a chegada ao laboratório, a amostra de sangue é ressuspendida, e então processada pelos testes sorológicos padrões para cada investigação de infecção. Esta metodologia teve validação por controle interno que observou sensibilidade e especificidade semelhantes aos métodos convencionais, conforme se observa na Tabela 1.

Tabela 1 - Sensibilidade e especificidade dos testes pela técnica do papel filtro.

\begin{tabular}{lcc}
\hline Testes & Sensibilidade (\%) & Especificidade (\%) \\
\hline HIV 1 e 2 & 99,9 & 99,8 \\
Toxoplasmose IgM & 99,4 & 99,8 \\
Toxoplasmose IgG & 99,3 & 99,8 \\
Citomegalovírus IgM & 100,0 & 99,7 \\
Citomegalovírus IgG & 99,6 & 100,0 \\
Doença de Chagas & 99,5 & 99,8 \\
Herpes simples 1 e 2 IgM & 100,0 & 98,9 \\
Herpes simples 1 e 2 IgG & 97,9 & 98,0 \\
Hepatite C & 98,1 & 99,5 \\
HBsAg & 99,7 & 99,8 \\
Anti-HBC & 99,5 & 99,8 \\
HTLV I e II & 100,0 & 99,9 \\
Sífilis & 98,9 & 99,9 \\
Rubéola IgM & 99,6 & 99,8 \\
Rubéola IgG & 99,6 & 99,8
\end{tabular}

Método: Ensaio Imunoenzimático (ELISA). Fonte: Instituto de Pesquisa, Ensino e Diagnóstico (IPED) da APAE.

Para o presente estudo, foram consideradas todas as gestantes com teste confirmatório positivo, de faixa etária livre, atendidas em todos os serviços médicos de pré-natal do Estado, que obtiveram diagnóstico de uma das infecções triadas, no período de novembro de 2002 e outubro de 2003.

As informações foram obtidas nos centros de atendimento médico destas pacientes (municipais, estaduais e federais), através de pesquisa em prontuários, contato telefônico direto com a maioria das gestantes e visita domiciliar quando necessário. 0 estudo foi aprovado pelo Comitê de Ética em Pesquisa da Universidade Federal do Mato Grosso do Sul.

A mensuração das variáveis foi expressa pelas médias, ao passo que a correlação entre algumas variáveis foi avaliada pelo teste do $\chi^{2}$ em tabelas de contingência de dupla entrada. Foi aceito $\mathrm{p}<0,05$ (95\%) como critério para rejeição da hipótese de nulidade.

\section{RESULTADOS}

As 32.512 gestantes triadas tinham entre 11 e 49 anos, com média de 23,8 4 4,2 anos. A faixa etária mais frequiente foi de 20-29 anos (53\%). Sendo que $15 \%$ estavam entre 30 e 39 anos, $2 \%$ acima de 40 anos e as menores de 19 anos representaram $30 \%$ da amostra. 
Quanto ao momento da triagem, 35,5\% foram triadas no $1^{\circ}$ trimestre, $32,4 \%$ triadas no $2^{\circ}$ trimestre e $32,1 \%$ no $3^{\circ}$ trimestre da gestação.

As frequiências observadas foram de $0,2 \%$ para infecção pelo vírus HIV-1, 0,1\% para rubéola IgM, 0,8\% VDRL e FTA/ABS reagentes, $0,4 \%$ para toxoplasmose $\mathrm{IgM}, 0,1 \%$ para infecção aguda pelo citomegalovírus (IgM), $0,1 \%$ pelo vírus herpes simples (IgM), 0,3\% gestantes com HBSAg reagente, $0,1 \%$ com anticorpo anti-HCV reagente, $0,1 \%$ com anticorpos anti-HTLV I/II reagentes e $0,1 \%$ para doença de Chagas, conforme pode ser observado na Tabela 2.

Tabela 2 - Frequiência das infecç̃̃es triadas pelo Programa de Proteção à Gestante de Mato Grosso do Sul (PPG-MS) nas gestantes do Estado, entre novembro de 2002 e outubro de 2003.

\begin{tabular}{lrc}
\hline & \multicolumn{2}{c}{ Gestantes } \\
\cline { 2 - 3 } Infecções & 71 & 0,2 \\
\hline HIV-1 & 10 & 0,1 \\
Rubéola & 252 & 0,8 \\
Síflis & 137 & 0,4 \\
Toxoplasmose & 15 & 0,1 \\
Citomegalovírus & 5 & 0,1 \\
Herpes simples 1 e 2 & 94 & 0,3 \\
Hepatite B (HBsAg) & 30 & 0,1 \\
Hepatite C & 43 & 0,1 \\
Doença de Chagas & 37 & 0,1 \\
HTLV I e II &
\end{tabular}

A taxa de positividade da infecção pelo vírus HIV-1 foi de $0,2 \%$, representando 71 gestantes com ELISA e Western-blot positivos para o vírus HIV-1. Destas, a faixa etária variou entre 16 e 42 anos, com média de 24,4 5,3 anos. Sendo que 88,6\% (46) das mesmas desconheciam seu estado de portadoras do vírus HIV-1 previamente à triagem pré-natal. As gestantes provenientes do interior do estado representaram $62 \%$ da amostra. Quanto à paridade, a maioria $(31,2 \%)$ das gestantes se encontrava na terceira gestação, sendo o segundo trimestre o período gestacional mais (45,5\%) prevalente da realização do diagnóstico. Não houve diferença estatística significativa entre a associação de faixa etária e presença da infecção pelo vírus HIV-1 entre as gestantes triadas no Estado de Mato Grosso do Sul, tanto nas pacientes submetidas inicialmente ao teste ELISA $(\mathrm{p}=0,17)$ quanto nas confirmadas com Western-blot $(\mathrm{p}=0,49)$, conforme pode ser observado na Tabela 3 .

A infecção aguda por rubéola (ELISA IgM) esteve presente em $10(0,03 \%)$ gestantes triadas, sendo encontradas 3.901 (12\%) susceptíveis. A idade variou de 18 a 28 anos com média de 21,3 $\pm 4,4$ anos. A idade gestacional média no momento do diagnóstico foi de 17,6 $6 \pm 1,2$ semanas. Nenhuma das gestantes com perfil IgM positivo tinha sido vacinada contra o vírus da rubéola previamente ou durante a gestação até o diagnóstico. Houve relação significativa $(\mathrm{p}<0,0001)$ entre idade materna e infecção pelo vírus da rubéola, demonstrando menos susceptibilidade à infecção, gestantes com idade superior a 31 anos, conforme dados expostos na Tabela 4.

Na investigação para sífilis, a positividade encontrada foi de $0,8 \%$ (252) de gestantes reagentes. A idade variou de 15 a 38
Tabela 3 - Freqüiência de anticorpos antivírus da imunodeficiência humana, de acordo com faixa etária, nas amostras de soro das gestantes submetidas à triagem pelo Programa de Proteção à Gestante de Mato Grosso do Sul entre novembro de 2002 e outubro de 2003.

\begin{tabular}{|c|c|c|c|c|c|c|c|c|}
\hline \multirow{4}{*}{$\begin{array}{l}\text { Faixa etária } \\
\text { (anos) }\end{array}$} & & & \multicolumn{6}{|c|}{ Testes } \\
\hline & & \multicolumn{4}{|c|}{ ELISA } & \multicolumn{3}{|c|}{ Western-blot } \\
\hline & \multicolumn{2}{|c|}{ reagente } & \multicolumn{2}{|c|}{ não reagente } & \multirow{2}{*}{$\begin{array}{r}\text { total } \\
\mathrm{n}^{0} \\
\end{array}$} & \multirow{2}{*}{$\begin{array}{c}\text { positivo } \\
n^{0}\end{array}$} & \multirow{2}{*}{$\begin{array}{c}\text { negativo } \\
n^{0}\end{array}$} & \multirow{2}{*}{$\begin{array}{r}\text { total } \\
\mathrm{n}^{0}\end{array}$} \\
\hline & $\mathrm{n}^{0}$ & $\%$ & $n^{0}$ & $\%$ & & & & \\
\hline$<21$ & 16 & 0,2 & 9.890 & 99,8 & 9.906 & 16 & 0 & 16 \\
\hline $21-30$ & 47 & 0,3 & 17.272 & 99,7 & 17.319 & 45 & 2 & 47 \\
\hline$>30$ & 11 & 0,2 & 5.276 & 99,8 & 5.287 & 10 & 1 & 11 \\
\hline Total & 74 & 0,2 & 32.438 & 99,8 & 35.512 & 71 & 3 & 74 \\
\hline
\end{tabular}

ELISA: $x^{2}=3.455$ e $p=0,17$. Western-blot: $x^{2}=1,39$ e $p=0,49$.

Tabela 4 - Freqüiência de positividade dos anticorpos das classes IgG e IgM anti-vírus da rubéola, segundo faixa etária, obtida por amostra de soro de gestantes submetidas à triagem pelo Programa de Proteção à Gestante de Mato Grosso do Sul entre novembro de 2002 e outubro de 2003.

\begin{tabular}{|c|c|c|c|c|c|c|c|c|c|}
\hline \multirow{4}{*}{$\begin{array}{l}\text { Faixa } \\
\text { etária } \\
\text { (anos) }\end{array}$} & \multicolumn{8}{|c|}{ Testes } & \multirow{4}{*}{$\begin{array}{r}\text { Total } \\
\mathrm{n}^{0}\end{array}$} \\
\hline & \multicolumn{4}{|c|}{ ELISA IgG } & \multicolumn{4}{|c|}{ ELISA IgM } & \\
\hline & \multicolumn{2}{|c|}{ reagente } & \multicolumn{2}{|c|}{ não reagente } & \multicolumn{2}{|c|}{ reagente } & \multicolumn{2}{|c|}{ não reagente } & \\
\hline & $\mathrm{n}^{0}$ & $\overline{\%}$ & $\mathrm{n}^{0}$ & $\%$ & $\overline{\mathrm{n}^{0}}$ & $\overline{\%}$ & $\mathrm{n}^{0}$ & $\overline{\%}$ & \\
\hline$<21$ & 7.259 & 73,3 & 2.647 & 26,7 & 6 & 0,1 & 9.900 & 99,9 & 9.906 \\
\hline $21-30$ & 16.118 & 93,1 & 1.201 & 6,9 & 4 & 0,1 & 17.315 & 99,9 & 17.319 \\
\hline$>30$ & 5.224 & 98,8 & 63 & 1,2 & 0 & 0,0 & 5.287 & 100,0 & 5.287 \\
\hline Total & 28.601 & 87,9 & 3.911 & 12,0 & 10 & 0,1 & 35.502 & 99,9 & 32.512 \\
\hline
\end{tabular}

anos com média de 24,5 $\pm 5,7$ anos, sendo $80,3 \%$ da amostra de gestantes proveniente do interior do estado.

A toxoplasmose aguda (IgM) esteve presente em 0,4\% (137) das gestantes (ELISA anti-Toxoplasma gondii IgM positivo). A exposição prévia ao parasita foi encontrada em $91 \%$ das gestantes, sendo 8\% susceptíveis. A faixa etária variou entre 14 e 37 anos, com média de 23 $\pm 5,9$ anos. A procedência predominante das gestantes foi do interior $(69,1 \%)$, sendo a maioria $(45,4 \%)$ primigesta. Quanto ao momento do diagnóstico, 48,1\% estavam no segundo trimestre gestacional. A epidemiologia positiva para toxoplasmose foi encontrada em $78,2 \%$ da amostra. 0 teste de avidez para anticorpos IgG demonstrou avidez elevada (>60\%) em $61,1 \%$ da amostra e avidez baixa (<30\%) em 8,7\%. Dentre as pacientes com IgM-ELISA positiva, 45 (32,6\%) foram submetidas à amniocentese para realização de PCR, sendo encontrado dois $(4,4 \%)$ resultados positivos, indicando doença fetal. A infecção congênita ocorreu em cinco de 104 recém-natos, que foram acompanhados no período neonatal. Não houve associação estatisticamente significativa, entre a idade das gestantes e a presença de infecção aguda pelo Toxoplasma gondii e pelo Treponema pallidum, conforme dados das Tabelas 5 e 6 . Das 253 gestantes com sífilis-ELISA reagente, apenas uma não apresentou positividade para o FTA-ABS IgG, confirmando a boa especificidade do teste em papel filtro.

A infecção aguda pelo citomegalovírus, obteve frequiência de $0,1 \%$ (15), sendo a mediana encontrada de avidez de IgG de $67,95 \pm 20,4 \%$. Encontrou-se uma susceptibilidade à infecção pelo CMV em $17,9 \%$ das gestantes, sendo $82 \%$ previamente expostas. 
Tabela 5 - Freqüência de positividade nos testes sorológicos para sífilis, por faixa etária, nas amostras de soro das gestantes triadas pelo Programa de Proteção à Gestante de Mato Grosso do Sul de novembro de 2002 a outubro de 2003.

\begin{tabular}{lrrrrrrr}
\hline \multirow{2}{*}{$\begin{array}{l}\text { Faixa } \\
\text { etária }\end{array}$} & \multicolumn{5}{c}{ Síflis-ELISA } & & \multicolumn{3}{c}{ FTA-ABS IgG } \\
\cline { 2 - 4 } \cline { 3 - 7 } (anos) & reagente & não reagente & $\mathrm{n}^{0}$ & & reagente & não reagente & $\mathrm{n}^{0}$ \\
\hline$<21$ & 73 & 9.833 & 9.906 & 73 & 0 & 73 \\
$21-30$ & 138 & 17.181 & 17.319 & & 137 & 1 & 138 \\
$>30$ & 42 & 5.245 & 5.287 & & 42 & 0 & 42 \\
\hline Total & 253 & 32.259 & 35.512 & 252 & 1 & 253 \\
\hline
\end{tabular}

Sífilis (ELISA): $x^{2}=0,31$ e $p=0,85$.

Tabela 6 - Relação entre idade das pacientes e a sorologia IgM para toxoplasmose.

\begin{tabular}{lccr}
\hline Idade (anos) & Sorologia IgM positiva & Sorologia IgM negativa & Total \\
\hline$\leq 14$ & 4 & 804 & 808 \\
$15-19$ & 39 & 9.059 & 9.098 \\
$20-29$ & 78 & 17.245 & 17.319 \\
$30-40$ & 16 & 4.779 & 4.793 \\
\hline Total & 137 & 31.887 & 32.024 \\
\hline$x^{2}=1,288$ e $p=0,73$. & & &
\end{tabular}

A média de idade das gestantes com IgM reagente para CMV foi de $20,7 \pm 4,5$ anos.

A sorologia ELISA IgM e IgG antivírus herpes simples 1 e 2 das gestantes triadas, revelou uma positividade do anticorpo IgM em $0,1 \%$ (5) da amostra, sendo 99,9\% (32.497) IgG positivo e $0,1 \%$ (10) IgG e IgM negativos. Houve associação significativa estatisticamente entre a idade das gestantes e infecção pelo vírus herpes simples e citomegalovírus no Estado de Mato Grosso do Sul. As gestantes mais jovens ( $<21$ anos) foram mais susceptíveis à infecção herpética aguda, enquanto as gestantes com idade superior a 30 anos foram menos susceptíveis à infecção pelo citomegalovírus, conforme dados expostos na Tabela 7.

Foi encontrada uma frequiência de 0,3\% (94) de gestantes com HBsAg reagente A média de idade ao diagnóstico foi de 24,2 44,8 anos, sendo a maioria $(76,4 \%)$ das gestantes provenientes do interior do estado. Quanto à paridade, as gestantes em sua

Tabela 7 - Freqüência de positividade de anticorpos antivírus berpes simples e anticitomegalovírus, de acordo com faixa etária, nas amostras de soros de gestantes submetidas à triagem pelo Programa de Proteção à Gestante de Mato Grosso do Sul de novembro de 2002 a outubro de 2003.

\begin{tabular}{|c|c|c|c|c|c|c|c|c|c|}
\hline \multirow{4}{*}{$\begin{array}{l}\text { Faixa } \\
\text { etária } \\
\text { (anos) }\end{array}$} & \multicolumn{8}{|c|}{ Testes } & \multirow{4}{*}{$\begin{array}{l}\text { Tota } \\
\mathrm{n}^{0}\end{array}$} \\
\hline & \multicolumn{4}{|c|}{ herpes simples vírus } & \multicolumn{4}{|c|}{ citomegalovírus } & \\
\hline & \multicolumn{2}{|r|}{ IgM } & \multicolumn{2}{|c|}{$\operatorname{IgG}$} & \multicolumn{2}{|c|}{$\operatorname{IgM}$} & \multicolumn{2}{|c|}{ IgG } & \\
\hline & $\mathrm{R}$ & NR & $\mathrm{R}$ & NR & $\mathrm{R}$ & NR & $\mathrm{R}$ & NR & \\
\hline$<21$ & 5 & 9.901 & 9.891 & 15 & 10 & 9.896 & 5.320 & 4.586 & 9.906 \\
\hline $21-30$ & 0 & 17.319 & 17.319 & 0 & 5 & 17.314 & 16.139 & 1.180 & 17.319 \\
\hline$>30$ & 0 & 5.287 & 5.287 & 0 & 0 & 5.287 & 5.202 & 85 & 5.2887 \\
\hline Total & 5 & 32.507 & 32.497 & 15 & 15 & 32.497 & 26.661 & 5.851 & 35.512 \\
\hline
\end{tabular}

Herpes simples vírus: ELISA IgM: $x^{2}=11,4 \mathrm{e} p=0,003$; ELISA IgG: $x^{2}=34,2$ e $p<0,0001$. Citomegalovírus: ELISA IgM: $x^{2}=190$ e $p=0,006$; ELISA IgG: $x^{2}=7805$ e $p<0,0001$.

R: reagente, NR: não reagente. maioria (41,6\%), encontravam-se na primeira gestação, sendo $01^{\circ}$ trimestre o período gestacional mais $(38,6 \%)$ prevalente da realização do diagnóstico de hepatite B. Além disso, 38 (95\%) das gestantes portadoras da infecção por hepatite $B$, apresentavam anticorpo anti-HBC reagente.

Quanto à infecção pelo vírus da hepatite C (VHC), houve $0,1 \%$ (30) de frequiência de gestantes com anticorpo anti-VHC reagente. A procedência do interior predominou em $66,7 \%$ da amostra, sendo a faixa etária variável de 17 a 34 anos com média de $25 \pm 4,1$ anos. Quanto à carga viral de VHC, foi encontrada uma média de $179.607 \pm 986$ UI. Não houve associação significativa entre idade das gestantes e presença de infecção pelos vírus das hepatites B e C na triagem, conforme dados da Tabela 8.

Tabela 8 - Freqüência de positividade de HbsAg e dos anticorpos antivírus Hepatite $C$, de acordo com faixa etária, nas amostras de soros de gestantes submetidas à triagem pelo Programa de Proteção à Gestante de Mato Grosso do Sul de novembro de 2002 a outubro de 2003.

\begin{tabular}{|c|c|c|c|c|c|c|c|c|c|}
\hline \multirow{4}{*}{$\begin{array}{l}\text { Faixa } \\
\text { etária } \\
\text { (anos) }\end{array}$} & \multicolumn{8}{|c|}{ Testes } & \multirow{4}{*}{$\begin{array}{r}\text { Total } \\
\mathrm{n}^{\circ}\end{array}$} \\
\hline & \multicolumn{4}{|c|}{ HBsAg } & \multicolumn{4}{|c|}{ Anti-HCV } & \\
\hline & \multicolumn{2}{|c|}{ reagente } & \multicolumn{2}{|c|}{ não reagente } & \multicolumn{2}{|c|}{ reagente } & \multicolumn{2}{|c|}{ não reagente } & \\
\hline & $\mathrm{n}^{0}$ & $\%$ & $\mathrm{n}^{0}$ & $\%$ & $\mathrm{n}^{0}$ & $\%$ & $\mathrm{n}^{0}$ & $\%$ & \\
\hline$<21$ & 25 & 0,2 & 9.881 & 99,7 & 7 & 0,1 & 9.899 & 99.9 & 9.906 \\
\hline $21-30$ & 56 & 0,3 & 17.263 & 99,7 & 19 & 0,1 & 17.300 & 99.9 & 17.319 \\
\hline$>30$ & 13 & 0,2 & 5.274 & 99,7 & 4 & 0,1 & 5.283 & 99.9 & 5.287 \\
\hline Total & 94 & 0,3 & 32.418 & 99,7 & 30 & 0,1 & 32.482 & 99.9 & 35.512 \\
\hline
\end{tabular}

HBSAg: $x^{2}=1,5$ e $p=0,46$. Anti-HCV: $x^{2}=1,23$ e $p=0,54$.

A doença de Chagas foi encontrada em $0,1 \%$ (43) das gestantes. A idade oscilou entre 15 e 40 anos, com média de $27,32 \pm 5,7$ anos. A idade gestacional (IG) média no momento do diagnóstico foi de 19,7 7 1,3 semanas. A epidemiologia positiva foi de 86\% (37) e uma concentração maior de casos (22) foi descoberta na região do cone sul do Estado, região sabidamente povoada por uma espécie de triatomínio, o Triatoma sordida. Alterações cardiovasculares como bloqueio de ramo foram encontradas em $30(69,7 \%)$ das gestantes, quatro delas apresentando sinais e sintomas de insuficiência cardíaca tendo sido acompanhadas paralelamente com o cardiologista. As gestantes com idade superior a 21 anos demonstraram maior reatividade aos testes sorológicos anti-Tripanosoma cruzi, sendo a associação entre idade avançada e sorologia positiva para doença de Chagas significativa estatisticamente $(\mathrm{p}<0,0001)$ conforme dados da Tabela 9.

A pesquisa de anticorpos anti-HTLV-I e II encontrou positividade em $0,1 \%$ (37) das gestantes triadas, com média de idade de $25,4 \pm 5,3$ anos, sendo a maioria $(78,4 \%)$ procedente do interior do estado. A infecção pelo HTLV predominou em multigestas (58\%), sendo 47\% da amostra diagnosticada no segundo trimestre gestacional. A história positiva de hemotransfusão ou amamentação na presença de infecção foi encontrada em 25\% da amostra. Em 25 (67,6\%) pacientes foi confirmada a infecção pela pesquisa de partícula viral através de PCR, sendo que em $51 \%$ das gestantes foi encontrado o genótipo I do HTLV e em $48 \%$ o tipo II. Em amostra sérica de 8 recém-natos, 
a pesquisa de PCR para HTLV foi positiva em 100\% dos casos, sendo que apenas uma criança recebeu aleitamento materno. Não houve associação significativa estatisticamente entre idade das gestantes e infecção pelo vírus HTLV na amostra estudada, conforme dados da Tabela 10.

Tabela 9 - Freqüência de positividade dos anticorpos anti-Trypanosoma cruzi, de acordo com a faixa etária, em amostras de soro de gestantes triadas pelo PPG-MS entre novembro de 2002 a outubro de 2003.

\begin{tabular}{lcccccc}
\hline \multirow{2}{*}{$\begin{array}{l}\text { Faixa etária } \\
\text { anos })\end{array}$} & \multicolumn{4}{c}{ Testes } & \\
\cline { 2 - 3 } & \multicolumn{2}{c}{ IFI-IgG +} & & \multicolumn{2}{c}{ ELISA IgG } & Total \\
\cline { 2 - 3 } & reagente & $\%$ & & não reagente & $\%$ & $\mathrm{n}^{0}$ \\
\hline$<21$ & 2 & 0,1 & & 9.904 & 100,0 & 9.906 \\
$21-30$ & 24 & 0,1 & & 17.295 & 99.8 & 17.319 \\
$>30$ & 17 & 0,3 & & 5.270 & 99,7 & 5.287 \\
\hline Total & 43 & 0,1 & & 32.469 & 99,9 & 32.512 \\
\hline
\end{tabular}

Doença de Chagas (IFI-IgG + ELISA IgG): $x^{2}=23,8$ e $p<0,0001$.

Tabela 10 - Associação entre a idade e a infecção materna pelo HTLV.

\begin{tabular}{lccr}
\hline Idade (anos) & Sorologia positiva & Sorologia negativa & Total \\
\hline $15-19$ & 5 & 9.093 & 9.098 \\
$20-29$ & 22 & 17.297 & 17.319 \\
$30-39$ & 7 & 4.786 & 4.793 \\
$40-49$ & 3 & 396 & 399 \\
\hline Total & 37 & 31.572 & 31.609 \\
\hline
\end{tabular}

HTLV: $x^{2}=0,74$ e $p=0,38$.

\section{DISCUSSÃO}

A literatura mostra evidências da importância em saúde pública de estudos soroepidemiológicos de doenças infecciosas transmissíveis verticalmente, as denominadas infecções congênitas e perinatais ${ }^{1924}$. Tanto estudos nacionais, realizados em Salvador $^{20}$, Campinas ${ }^{3}$, Ribeirão Preto ${ }^{9}$ e Londrina ${ }^{19}$, como estudos internacionais como o de Salamanca ${ }^{24}$ (Espanha) enfatizam a necessidade de triagem abrangente das mais diversas infecções passíveis de TV o mais precocemente possível durante o período pré-natal. Tal triagem age como forma de programar medidas de saúde preventivas que alcancem de modo mais efetivo o controle de TV nas diversas populações.

Com a mudança epidemiológica da infecção pelo vírus HIV-1 o qual passou a atingir cada vez mais mulheres em idade fértil, as gestantes com infecção pelo vírus HIV-1 são potenciais transmissoras do vírus aos fetos e recém-nascidos. Sua detecção e tratamento precoce no período gestacional possibilita impedir a ocorrência da transmissão vertical ${ }^{9}{ }^{19}$, o que justifica e embasa a pesquisa anti-HIV no pré-natal. A positividade da infecção pelo HIV no presente estudo foi de $0,2 \%$, associado a alto índice de desconhecimento das gestantes da condição de portadoras do vírus em $88 \%$ dos casos. Offor e cols, na Nigéria ${ }^{17}$, obtiveram $2,4 \%$ de frequiência de sorologia para HIV-1 em gestantes, partindo de pesquisa em mulheres grávidas voluntárias, através de divulgação pública prévia dos testes. Em Salamanca ${ }^{24}$, encontrou-se um índice de $0,2 \%$, semelhante ao presente estudo, sendo que $15 \%$ destas pacientes não sabiam sua condição de portadoras. No Brasil, em Londrina, a frequiência de infecção pelo HIV-1 em gestantes foi de $0,6 \%{ }^{19}$, em Campinas de $0,3 \%^{3}$ e em Salvador foi de $0,1 \%{ }^{20}$. Nestes estudos, partiu-se de populações atendidas em serviços secundários e terciários. No estudo de Londrina ${ }^{19}$, também, não houve associação estatística significante entre idade materna e infecção pelo HIV-1.

No Brasil, a exemplo de outros países como o Reino Unido ${ }^{22}$, a vacinação de rubéola em mulheres motivou campanhas maciças contribuindo para a redução de casos agudos da doença, protegendo as pacientes susceptíveis. No Estado de Mato Grosso do Sul, houve ampla campanha vacinal entre 2001 e 2002, atingindo altos índices de cobertura, o que pode ter contribuído na freqüência de anticorpos anti-rubéola IgM durante o período gestacional $(0,1 \%)$. A frequiência avaliada no presente estudo esteve abaixo de valores obtidos em Londrina $^{19}$ (1,2\% IgM e $89 \% \operatorname{IgG}$ ), entretanto, $12 \%$ das gestantes de MS encontravam-se susceptíveis, contra 11\% de susceptíveis de Londrina. No Estudo de Salamanca ${ }^{24}$, a taxa de exposição prévia a rubéola foi de 99,9\%, devido a grande campanha de vacinação promovida naquele país. Não foi observada em estudo semelhante ${ }^{19}$, associação estatística significativa entre idade e frequiência dos casos de rubéola em gestantes.

A taxa de positividade de sífilis no nosso estudo foi de $0,8 \%$, abaixo dos valores encontrados em Londrina ${ }^{19}(1,6 \%)$, Salvador $(3,9 \%)^{20}$, São Paulo $(5,6 \%)^{4}$, no Chile $(2,3 \%)^{5}$ e Nigéria $(1,7 \%)^{1}$, mas, superior ao encontrado em Salamanca ${ }^{24}(0 \%)$. Exceto 0 estudo de Salamanca, os demais trabalhos também partiram de populações de serviços terciários ou de pacientes voluntárias ${ }^{17}$. Na região sul ${ }^{19}$, a frequiência de sífilis durante a gestação varia em torno de $2 \%$, considerando os testes VDRL confirmados com o FTA/ABS IgG. Também não foi observada associação estatística significante entre idade e presença de sífilis nas gestantes de Londrina ${ }^{19}$.

Quanto à detecção de anticorpos $\operatorname{IgG}$ anti-Toxoplasma gondii, presentes em 91\% da amostra estudada, esse valor se encontra acima dos níveis descritos na literatura, talvez pelas características sócio-econômicas do Estado de MS, relacionadas aos hábitos de manipulação e ingestão de carne crua e contato com animais domésticos. Em contrapartida, a susceptibilidade baixa de $8 \%$ das gestantes à infecção pelo toxoplasma demonstra o alto grau de exposição no nosso meio e a frequiência observada foi de 0,4\% de gestantes com infecção aguda de toxoplasmose. Em Londrina $^{19}$, foi observada exposição prévia em $67 \%$ das gestantes e susceptibilidade em 33\%, com 1,8\% de casos agudos. No Brasil, existem taxas de anticorpos da classe IgG anti-Toxoplasma gondii em mulheres em idade reprodutiva variando de 60 a $75 \%$, sendo os casos susceptíveis variando de 20 a $40 \%{ }^{19}$. Na Europa, a seleção sorológica de rotina é regulamentada por lei em países como França e Áustria, o que contribuiu para redução da transmissão congênita de toxoplasmose ${ }^{19}$. Em Salamanca ${ }^{24}$, a exposição prévia foi detectada em apenas $18,8 \%$ de 2.929 gestantes triadas no serviço. Não houve associação estatística significativa entre faixa etária e toxoplasmose materna em estudo semelhante realizado em gestantes no estado do Paraná19. 
0 citomegalovírus pode causar sérios comprometimentos ao desenvolvimento do sistema nervoso fetal, sendo fundamental a sua pesquisa em gestantes. No presente estudo, observou-se $0,05 \%$ de casos IgM reagentes para CMV, sendo 17,9\% das gestantes susceptíveis e $82 \%$ previamente expostas. Em trabalho realizado no Espírito Santo em 2004, Spano e cols ${ }^{21}$ obtiveram uma frequiência de $0,2 \%$ de casos agudos de CMV. Na Itália, Lazzaroto e cols ${ }^{13}$ encontraram anticorpos da classe IgM para CMV em 5,7\% das gestantes triadas. Não foram encontrados na literatura, dados descritos associando faixa etária e infecção pelo citomegalovírus em gestantes.

A infecção pelo vírus herpes simples 1 e 2 na gestação pode ocasionar infecção do RN no momento do parto. Em nosso estudo, foi obtida uma positividade de $0,02 \%$ de casos agudos, sendo $99,9 \%$ (32.497) de casos expostos previamente e $0,1 \%$ (10) não expostos. No mundo estas taxas variam de região a região, sendo encontrado $0,1 \%$ de casos de herpes aguda em gestantes belgas ${ }^{7}$ dentre 35.940 sorologias analisadas, com 95,5\% de exposição prévia. Na Noruega por sua vez, Eskid e cols ${ }^{10}$ encontraram uma frequiência de 4\% de casos agudos de infecção herpética e 93,4\% de expostos. Também, não foram encontrados descritos, dados associando idade materna e infecção herpética.

A presença do antígeno de superfície do vírus da hepatite $B$ (HBsAg) em 0,3\% das gestantes triadas pelo PPG-MS, está dentro da faixa de positividade encontrada em estudos nacionais em adultos (0,3-13\%) e em gestantes $(0,3-1,7 \%)^{919}$. A frequiência de HBsAg em gestantes foi de $0,8 \%$ em Londrina ${ }^{19}, 0,5 \%$ em Goiânia ${ }^{8}$, e 0,3\% em Salvador ${ }^{20}$. Na Espanha ${ }^{24}$ observou-se a presença de $0,4 \%$ de HBsAg em gestantes, sendo que $54 \%$ destas desconheciam sua condição sorológica previamente ao pré-natal. Em Cuba, Fernandes e cols ${ }^{16}$ encontraram $0,3 \%$ de casos de HBsAg em grávidas, semelhante a observada nas gestantes do Estado de Mato Grosso do Sul.

Afrequiência de anticorpos anti-vírus da hepatite C (VHC) em nosso estudo foi de $0,1 \%$, inferior à detectada em estudos com gestantes em Londrina $(0,8 \%)^{19}$, Ribeirão Preto $(0,6 \%)^{9}$ e Espanha $(0,4-1,2 \%)^{11,24}$. No Zimbáwbe, Madzime e cols ${ }^{15}$ encontraram $1,6 \%$ de casos de hepatite $\mathrm{C}$ em gestantes. Mundialmente, porém, há uma estimativa de positividade de anticorpos anti VHC variando entre 0,1 e 2,4\% em mulheres grávidas ${ }^{19}$, podendo ser maior em áreas endêmicas. Apesar destes índices, a literatura demonstra ser pequena a taxa de transmissão vertical, ressaltando a necessidade de confirmação diagnóstica com PCR ou imunoblot em função dos falsos-positivos pelo teste ELISA ${ }^{919}$. Quanto à associação, entre idade materna e presença de HBsAg e ou anticorpos anti-VHC, não houve significância estatística em estudo nacional com metodologia semelhante?

A doença de Chagas ainda constitui no Brasil significativo problema da saúde pública. Com o controle mais freqüente da transmissão por hemotransfusão e transmissão vetorial, a transmissão transplacentária maternofetal tem assumido posição mais relevante. Na América Latina, sua transmissão congênita apresenta incidência variando de 0 a $11,5 \%{ }^{9}$, sendo que em média, apenas $1 \%$ das mulheres infectadas transmite a doença, o que justifica sua pesquisa no período pré-natal. A frequiência encontrada foi de $0,1 \%$ em gestantes do Estado de Mato Grosso do Sul, ficando próximo àquela encontrada em estudos com gestantes de Londrina $(0,9 \%)^{19}$ e abaixo da freqüência encontrada em Salvador $(2,3 \%)^{20}$, apesar destes estudos serem centralizados em serviços de nível secundário e terciário de atendimento em saúde. A associação estatística significativa encontrada entre idade avançada das mulheres grávidas e presença de anticorpos antitripanossomíase americana também foi observada em estudo brasileiro realizado em Londrina ${ }^{19}$.

A infecção pelo HTLV foi diagnosticada em 0,1\% das gestantes triadas em nosso estudo, o que está dentro da faixa de frequiência observada em regiões não-endêmicas para a infecção. Os índices de frequiência em gestantes variam nos estudos em 3,7\% no Japão $0^{12}, 2,3 \%$ no Peru ${ }^{25}$ e entre 2,8\% e 8,3\%, conforme faixa etária, na Guiana Francesa ${ }^{23}$, regiões endêmicas para infecção pelo HTLV. No entanto, em trabalho desenvolvido por Ades e cols ${ }^{2}$, pode-se evidenciar claramente a associação da infecção pelo HTLV em relação com fatores de risco, sendo o principal deles a origem étnica e demográfica. Em crianças nascidas de gestantes caribenhas, a soroprevalência foi de 17 por 1.000 , entre gestantes de origem africana foi de 3,2/1.000, em gestantes negras de origem caribenha de 6,8/1.000 e nas crianças cujas mães e pais nasceram em regiões não-endêmicas a soroprevalência foi de $0,1 / 1.000$. Por fim os autores estimaram que 223 entre 720.000 gestantes, encontram-se infectadas pelo HTLV (CI 95\% 110 a 350). No Brasil, considerada região não-endêmica, obteve-se dados de soroprevalência em gestantes de Salvador de $0,8 \%{ }^{6}$ e em Botucatu de $0,1 \%{ }^{18}$. Na Espanha, em estudo abrangendo 20.366 gestantes de 12 cidades, observou-se uma prevalência de $0,1 \%$ (13/20.366) de infecção pelo HTLV confirmada pelo método PCR ${ }^{14}$. Não foram encontrados na literatura, dados sobre associação entre faixa etária materna e freqüiência de infecção pelo HTLV.

As taxas de frequiência de rubéola, sífilis, toxoplasmose, doença de Chagas e CMV nas gestantes sul-matogrossenses encontramse abaixo dos valores descritos na literatura. A ocorrência de HIV, HTLV (em áreas não-endêmicas) e das hepatites B e C não apresentam diferenças quando comparadas aos dados disponíveis. Vale ressaltar que não há na literatura mundial ampla triagem pré-natal comparativamente ao presente estudo.

Houve associação estatística significativa entre idade das gestantes e as infecções pré-natais por rubéola, CMV, doença de Chagas e herpes vírus. Não houve associação significativa entre a faixa etária das gestantes triadas e as infecções HIV-1, sífilis, toxoplasmose, HTLV e hepatites B e C.

Em última análise, destaca-se a metodologia de triagem sorológica pré-natal inédita, utilizando o método do papel filtro, para diagnóstico de 10 infecções de importância na saúde materno-fetal, ressaltando a sua necessidade e importância de realização no período pré-natal.

\section{REFERÊNCIAS}

1. Aboyeji AP, Nwabuisis C. Prevalence of sexually transmitted diseases among pregnant women in Ilorin, Nigeria. Journal of Obstetric Gynaecology 23:637-639, 2003.

2. Ades AE, Parker S, Walker J, Edginton M, Taylor GP, Weber JN. Human T cell leukaemia/lymphoma virus infection in pregnant women in the United Kingdom: population study. British Medical Journal 3:1497-1501, 2000. 
3. Amaral E, Faúndes A, Gonçales NSL, Pellegrino JJ, Souza CA, Silva JLP. Prevalence of HIV and treponema pallidum infections in pregnant women in Campinas e their association with socio-demographic factors. São Paulo Medical Journal 114:1108-1116, 1996

4. Barsanti C, Valderato F, Diniz EMA, Succi RCM. Diagnóstico de síflis congênita: comparação entre testes sorológicos na mãe e no recém-nascido. Revista da Sociedade Brasileira de Medicina Tropical 32:605-611, 1999.

5. Bernal J, Arroyo 0, Garcia MA. Detección de sífilis en la embarazada/Syphilis at pregnancy. Revista chilena obstetricía y Ginecología 51:124-132, 1986.

6. Bittencourt AL, Dourado I, Filho PB, Santos M, Valadao E, Alcântara LC, GalvãoCastro B. Human T-cell lymphotropic virus type 1 infection among pregnant women in northeastern Brazil. Journal of Acquired Immune Deficience Syndrome15:490-494, 2001.

7. Bodeus M, Laffineur K, Kabamba-Mukadi B, Hubinont C, Bernard P, Goubau P. Seroepidemiology of herpes simplex type 2 in pregnant women in Belgium. Sexual Transmition Disease 31:297-300, 2004.

8. Cardozo DDP, Faria EL, Azevedo MSP, Queiroz DAO, Martins RMB, Souza TT, Daher RR, Martelli CMT. Soroepidemiologia para o vírus da hepatite B em gestantes/ parturientes e sua transmissão para os recém nascidos em Goiânia, G0. Revista da Sociedade Brasileira de Medicina Tropical 29:349-353, 1996.

9. Duarte G (ed) Diagnóstico e Conduta nas Infecções Ginecológicas e Obstétricas. Funpec Editora, Ribeirão Preto, 2003.

10. Eskild A, Jeansson S, Stray-Pedersen B, Jenum PA. Herpes simplex virus type-2 infection in pregnancy: no risk of fetal death: results from a nested case-control study within 35,940 women. British Journal of Obstetrics and Gynaecology 109:1030-1035, 2002.

11. Ibarra FJ0, Damian RF, Sanchez JL. Prevalencia de marcadores serológicos de los virus de la hepatitis A, B, C, y D en embarazadas. Salud Pública del México 38:317-322, 1996.

12. Kashiwagi K, Furusyo N, Nakashima H, Kubo N, Kinukawa N, Kashiwaqi S, Haiyashi $\mathrm{J}$. A decrease in mother-to-child transmission of human T lymphotropic virus type I (HTLV-I) in Okinawa, Japan. The American Journal of Tropical Medicine and Hygiene 70:158-163, 2004

13. Lazzarotto T, Gabrielli L, Lanari M. Congenital cytomegalovirus infection: recent advances in the diagnosis of maternal infection. Humman Immunology 65:410452,2004 .

14. Machuca A, Tuset C, Soriano V, Caballero E, Aguilera A, Ortiz de Lejarazu R. Prevalence of HTLV infection in pregnant women in Spain. HTLV Spanish Study Group. Sexually Transmitted Infections 76:366-370, 2000.
15. Madzime S, William MA, Mohamed K, October T, Adem M, Mudzamiri S, Woelk GB. Seroprevalence of hepatitis $\mathrm{C}$ virus infection among indigent urban pregnant women in Zimbabwe. Central African Journal of Medicine 46:01-04, 2000.

16. Millian RF, Brooks GVS, Machin LF. Gestantes con antígeno de superficie positivo: resultado de su pesquisaje en 5.837 casos. Revista Cubana Higiene y Epidemiologia 37:61-65, 1999.

17. Offor JUE, Onakewhor FE, Okonofua E. Maternal and neonatal seroprevalence of human immunodeficiency virus antibodies in Benin City, Nigeria. Journal of Obstetric Gynaecology 20:589-599, 2000.

18. Olbrich Neto J, Meira DA. Soroprevalência de vírus linfotrópico de células T humanas, vírus da imunodeficiência humana, sífilis e toxoplasmose em gestantes de Botucatu - São Paulo - Brasil. Fatores de risco para vírus linfotrópico de células T humanas. Revista da Sociedade Brasileira de Medicina Tropical 37:28-32, 2004.

19. Reiche EMV, Morimoto HK, Farias GN, Hisatsugu KR, Geller L, Gomes ACLF, Inoue HY, Rodrigues G, Matsuo T. Prevalência de tripanossomíase americana, sífilis, toxoplasmose, rubéola, hepatite $\mathrm{B}$, hepatite $\mathrm{C}$ e da infecção pelo virus da imunodeficiência humana, avaliada por intermédio de testes sorológicos, em gestantes atendidas no período de 1996 a 1998 no hospital Universitário Regional Norte do Paraná (Universidade Estadual de Londrina, Paraná, Brasil). Revista da Sociedade Brasileira de Medicina Tropical 33:519-527, 2000.

20. Santos JI, Lopes MAA, Deliege-Vasconcelos E, Couto Fernandez JC, Patel BN Barreto ML, Ferreira Junior OC, Galvao Castro B. Seroprevalence of HIV, HTLV I/II and other perinatally-transmitted pathogens in Salvador- Bahia. Revista do Instituto de Medicina Tropical de São Paulo 37:343-348, 1995.

21. Spano LC, Gatti J, Nascimento JP, Leite JP. Prevalence of human cytomegalovirus infection in pregnant and non-pregnant women. Journal of Infectology 48:213-220, 2004

22. Tookey PA, Cortina-Borja M, Peckhmam CS. Rubella susceptibility among pregnant women in North London, 1996-1999. Journal of Public Health Medicine 24:211-216, 2002

23. Torteyoye P, Tuppin P, Peneau C. Decrease of human T-cell lymphotropic virus type I prevalence and low incidence among pregnant women from a high endemic ethnic group in French Guiana. International Journal of Cancer 87:534-538, 2000.

24. Zufiarre NG, Hernandez JS, Muños S. Seroprevalencia de anticuerpos frente a Treponema pallidum, Toxoplasma gondii, virus de la rubéola, virus de la hepatitis B y C y VIH en mujeres gestantes. Enfermedades Infecciosas y Microbiología Clínica 22:512-516, 2004.

25. Zurita S, Costa C, Watts D, Indacochea S, Campos P, Sanchez J, Gotuzzo E. Prevalence of human retroviral infection in Quillabamba and Cuzco, Peru: a new endemic area for human T cell lymphotropic virus type 1. American Journal of Tropical Medicine and Hygiene 56:561-565, 1997. 